\title{
OS SIGNIFICADOS DO TRABALHO SEGUNDO TÉCNICOS DE NÍVEL MÉDIO
}

\author{
SUZANA BURNiER*
}

RESUMO: Baseando-nos numa pesquisa realizada com duas geraçóes de técnicos de nível médio, buscamos compreender os diálogos que esse segmento de trabalhadores estabelece com o mundo do trabalho no contexto da modernidade tardia. São aqui discutidos os significados por eles conferidos ao trabalho, no contexto da reestruturação produtiva. Como tal processo é percebido por esse grupo de trabalhadores qualificados? Como percebem as atividades por eles exercidas nas empresas? Em que medida são "cooptados" ou não pelos discursos patronais? Que condiçôes demandam para estabelecerem uma relação positiva com o trabalho? Que tipos de relações sociais vivenciam no trabalho e como as analisam? Pretende-se com o estudo contribuir para a reflexão acerca dos processos formativos de trabalhadores, escolares ou não, indicando os temas apontados pelos próprios trabalhadores como centrais na sua experiência e, portanto, merecedores de análise durante sua formação.

Palavras-chave: Trabalhadores qualificados. Representações. Significados.

THE MEANINGS OF WORK ACCORDING TO TECHNICIANS WITH SECONDARY EDUCATION

ABSTRACT: Based on a research focusing on two generations of technicians with secondary education, we sought to understand the dialogues that this segment of workers establishes with the world of work in late modernity. We here discuss the meanings they attribute to work in a context of productive restructuring. How is such process felt by this group of qualified workers? How do they perceive the activities they perform in their companies? To what extent are

* Doutora em Educação Brasileira pela Pontifícia Universidade Católica do Rio de Janeiro (PUCRIO) e professora do Mestrado em Tecnologia do Centro Federal de Educação Tecnológica (CEFET) de Minas Gerais. E-mail: sburnier@poboxes.com 
Os significados do trabalho segundo técnicos de nível médio

they "co-opted" by employer discourses? Which conditions do they claim to establish a positive relationship to work? In what kind of social relationships do they live at work and how do they analyze them? This study intends to contribute to a reflection on the training processes of workers, be they educational or not, by pointing out the topics the very workers highlighted as crucial in their experience and which, therefore, deserve analysis during their training.

Key words: Qualified workers. Representations. Meanings.

$\mathrm{O}$

s dados em que se baseiam as análises aqui apresentadas são oriundos de uma pesquisa realizada com duas gerações de técnicos de nível médio: uma formada em 1986 e outra, em 1996. Esses técnicos foram identificados a partir das listas de formados numa tradicional instituição educativa especializada nessa modalidade de ensino, localizada numa das cinco maiores regiões metropolitanas do país. A Figura 1 fornece dados acerca da origem socioeconômica desses sujeitos, indicando as profissões de seus pais.

A necessidade de um tal estudo dialoga com os debates acerca das recentes mudanças na sociedade e no mundo do trabalho, com o surgimento do conjunto de fatos denominados por autores do porte de Alain Touraine (1994) e Anthony Giddens (1997) como modernidade tardia: desenvolvimento científico e tecnológico integrando praticamente todo o planeta, promovendo a desterritorialização das identidades, a superação da centralidade do Estado-nação com a internacionalização da economia, o crescimento sem precedentes dos setores terciários da economia em detrimento da hegemonia do setor secundário, o crescimento material e ainda do peso simbólico do consumo e das comunicações, tudo isso associado a significativas mudanças na produção, conhecidas como o advento das novas tecnologias de produção e de gestão.

Este estudo visa a contribuir para esse debate, focalizando um grupo específico de trabalhadores, os técnicos de nível médio, numa abordagem metodológica que busca privilegiar o olhar dos sujeitos sobre as situaçôes vividas. A fim de captar as concepções próprias dos técnicos sobre o trabalho, fizemos a opção metodológica de não os abordar a partir do local de trabalho, buscando assim contornar os "efeitos entrevista" que poderiam contaminar nossos dados, uma vez que, ao acessar os trabalhadores no seu local de trabalho, estaríamos, inevita- 
Suzana Burnier

\section{Figura 1}

(Atividade profissional dos pais dos técnicos quando de seu ingresso no curso técnico)

\begin{tabular}{|c|c|c|}
\hline Tipo de atividade & Pai & Mãe \\
\hline Agricultor (pequeno proprietário) * & 1 & \\
\hline Do lar* & & 10 \\
\hline Empregada doméstica * & & 1 \\
\hline Camelô * & 1 & \\
\hline Taxista (proprietário e motorista) ${ }^{*}$ & 1 & \\
\hline Proprietário de táxi ${ }^{*}$ & & 1 \\
\hline Auxiliar de escritório * & 1 & \\
\hline Balconista ${ }^{* *}$ & 3 & \\
\hline Funcionário público federal não qualificado ** & & 1 \\
\hline Ferroviário ${ }^{* *}$ & 1 & \\
\hline Motorista de ônibus urbano ** & 1 & \\
\hline Depiladora $^{* *}$ & & 1 \\
\hline Petroleiro (técnico de nível médio) *** & 1 & \\
\hline Auxiliar de enfermagem ${ }^{* * *}$ & & 1 \\
\hline Operário metalúrgico $* * *$ & 4 & \\
\hline Professora primária da rede estadual ${ }^{* * *}$ & & 1 \\
\hline Microempresário *** & 1 & \\
\hline Professor universitário ${ }^{* * * *}$ & 1 & 1 \\
\hline Sem dados & 2 & 1 \\
\hline TOTAL & 18 & 18 \\
\hline
\end{tabular}

* Profissōes não-qualificadas; ** Profissōes semiqualificadas;

*** Profissóes qualificadas; ${ }^{* * * *}$ Profissōes liberais (segundo Pastore \& Valle Silva, 1999)

Fonte: Entrevistas

velmente, acionando de dentro os discursos e jogos de poder aí presentes, o que, certamente, interviria nos dados assim coletados. Optamos, pois, por alcançar nossos sujeitos em casa, obtendo seus endereços a partir de uma escola profissionalizante. Selecionamos três cursos: mecânica, eletrotécnica e eletrônica, e localizamos 18 sujeitos neles for- 
Os significados do trabalho segundo técnicos de nível médio

mados ( 15 homens e 3 mulheres). Ao longo dos três anos de pesquisa, nove técnicos concluíram o curso superior e seis estavam cursando a universidade, e apenas um deles em instituição pública. Objetivando captar as possíveis transformações em suas experiências no mercado e em suas representações sobre o trabalho e evitando tomar como definitivas posições que poderiam ser momentâneas, acompanhamos esses sujeitos ao longo de três anos (entre 2001 e 2003), durante os quais os contatamos por meio de entrevistas, telefonemas e e-mails, tendo sido privilegiadas as primeiras.

Nosso interesse, neste texto, será discutir como o mercado de trabalho tem sido vivenciado pelos técnicos de nível médio das duas gerações investigadas: que condições de trabalho eles vêm encontrando e como as avaliam? Em que tipo de relações sociais no trabalho eles se vêm inseridos e que significado elas possuem para esses sujeitos? Que temas e problemas se mostram fundamentais em seu cotidiano e deveriam ser trabalhados nos programas de formação escolares, sindicais e sociais?

\section{Os contextos de trabalho dos investigados}

Os técnicos investigados trabalham em empresas de diferentes tipos e tamanhos (Figura 2), predominando os trabalhadores metalúrgicos (dez). Entre esses, oito trabalham em empresas multinacionais de médio ou grande porte.

Também estão presentes outros tradicionais empregadores de mãode-obra especializada, as antigas estatais, aqui representadas pelos setores de telecomunicações, energético e de distribuição de água, também altamente "tecnologizados".

Os salários desses técnicos variam entre a faixa de 4 a 5 salários mínimos (dois técnicos não registrados como tal nas carteiras de trabalho) e a faixa de 21 a 26 salários mínimos (recebidos por três técnicos que alçaram postos de gerência: um em siderúrgica, outro em indústria de autopeças e um terceiro em distribuidora de energia). A média salarial dos que permanecem como técnicos no mercado é de 8,7 salários mínimos, o que pode parecer uma boa remuneração mas que, na verdade, não passa de 1,5 salário mínimo necessário. ${ }^{1}$

Como 60\% dos entrevistados encontram-se na faixa acima de dez salários mínimos, o que corresponde a 6,7\% dos ocupados brasileiros, 
poder-se-ia pensar que eles constituem um grupo privilegiado. Entretanto, é necessário considerar que 11 entre os entrevistados recebem até 1,5 salário mínimo necessário, o que demonstra as efetivamente limitadas condições financeiras em que se encontra essa "elite" dos trabalhadores brasileiros.

\section{Figura 2}

(Local de trabalho dos entrevistados)

\begin{tabular}{|c|c|c|}
\hline Tipo de empresa & Setor & $\begin{array}{l}\text { Número de } \\
\text { entrevistados }\end{array}$ \\
\hline \multirow{3}{*}{$\begin{array}{l}\text { Empresas de capital } \\
\text { misto, ex-estatais }\end{array}$} & Telecomunicações & 2 \\
\hline & $\begin{array}{l}\text { Produção e } \\
\text { distribuiçãa de } \\
\text { energia }\end{array}$ & 4 \\
\hline & $\begin{array}{l}\text { Tratamento e } \\
\text { distribuição de água }\end{array}$ & 1 \\
\hline \multirow{6}{*}{ Empresas privadas } & Eletroeletrônicos & 1 \\
\hline & Autopeças & 3 \\
\hline & Siderúrgicas & 3 \\
\hline & $\begin{array}{l}\text { Comércio e } \\
\text { manutenção de } \\
\text { equipamentos para } \\
\text { sistemas de energia }\end{array}$ & 1 \\
\hline & $\begin{array}{l}\text { Instalação e } \\
\text { manutenção de TV a } \\
\text { cabo }\end{array}$ & 1 \\
\hline & Estruturas metálicas & 2 \\
\hline
\end{tabular}

Fonte: Entrevistas.

Em termos de lugar na hierarquia empresarial, os entrevistados distribuem-se conforme a Figura 3.

Predominam os postos até o nível técnico, que inclui os postos de supervisão (14 casos). Observamos entre esses seis técnicos que, apesar de possuírem hoje formação superior, não encontraram colocação compatível no mercado e continuam atuando como técnicos de nível médio. 
Os significados do trabalho segundo técnicos de nível médio

\section{Figura 3}

(Posição dos entrevistados na hierarquia das empresas)

\begin{tabular}{|l|c|}
\hline \multicolumn{1}{|c|}{ Posição da hierarquia } & \multicolumn{1}{c|}{$\begin{array}{c}\text { Número de } \\
\text { entrevistados }\end{array}$} \\
\hline $\begin{array}{l}\text { Postos semiqualificados } \\
\text { (eletricista, almoxarife) }\end{array}$ & 2 \\
\hline $\begin{array}{l}\text { Postos técnicos na produção } \\
\text { (técnico de manutenção) }\end{array}$ & 4 \\
\hline $\begin{array}{l}\text { Postos técnicos no escritório } \\
\text { (desenhista; monitoramento de } \\
\text { operaçōes) }\end{array}$ & 3 \\
\hline Postos de supervisão & 3 \\
\hline Postos de gerência & 1 \\
\hline Postos administrativos & 5 \\
\hline
\end{tabular}

Fonte: Entrevistas.

\section{Os sentidos do trabalho}

Os entrevistados, de ambas as geraçôes (formados em 1986 e em 1996), terminaram seus cursos técnicos com uma expectativa muito positiva com relação ao mercado de trabalho. "Agora abriram-se as portas." Em virtude do curso técnico, com alto nível de exigências acadêmicas, e ainda do "nome" construído no mercado pela escola em que se formaram, eles demonstravam uma auto-imagem de trabalhadores bastante positiva e confiante em "ser técnico, provar minha competência e fazer sucesso".

Observaremos entretanto uma redefinição dessas expectativas, baseada nos salários, na complexidade das tarefas executadas e no tipo de relaçôes sociais vividas no trabalho.

\section{O significado dos salários}

Os salários, variando muito, contribuirão de diferentes maneiras para a construção de significados para o trabalho. Obviamente, os que alcançaram melhor remuneração tendem a conferir um sentido positi- 
vo ao trabalho, ainda que este não seja o único eixo definidor desses significados.

Podemos constatar que a geração dos formados em 1996 se encontra menos satisfeita com os salários: em parte porque, com menor tempo de mercado, ainda não tiveram o mesmo número de oportunidades que os formados em 1986. Em contrapartida, é importante destacar que, se na década de 1980 inúmeras empresas vinham à escola profissionalizante arregimentar trabalhadores antes mesmo da conclusão do curso, quando estes eram encaminhados, com freqüência, para postos de supervisão; hoje, muitas vêm substituindo os operadores de máquinas por técnicos, enxugando os postos de supervisão e substituindo chefias intermediárias, antes exercidas por técnicos, por trabalhadores com formação superior. Assim, a média salarial dos formados em 1986 é de 14,7 salários mínimos ao passo que a média dos salários dos formados em 1996 está na faixa de 6,8 salários mínimos.

A média geral dos salários dos entrevistados é de 8,7 salários mínimos, o que corresponde a um valor aquém de suas expectativas: "Ter casa própria, carro bom, escola particular para os filhos e viagem de férias". Este é um dos fatores que os impele para o curso superior, o que vemos acontecer somente depois de alguns anos como técnicos no mercado. $\mathrm{O}$ fato de não se encaminharem para a universidade imediatamente após a conclusão do curso técnico (a média geral é de ingresso na universidade seis anos após a conclusão do curso técnico) comprova sua esperança inicial de alcançarem o padrão de vida desejado com o diploma de técnico.

Os salários configuram-se então como fator de desconstrução do significado positivo inicialmente construído para o trabalho como técnico de nível médio, na grande maioria, ainda que não na totalidade dos casos investigados. Observa-se também um aumento da relevância desse fator, na segunda geração investigada.

\section{O significado do tipo de ocupação exercida}

A avaliação dos técnicos acerca das ocupaçōes exercidas demonstra que eles conferem grande importância à complexidade das tarefas cotidianamente desempenhadas. Surpreendentemente, para um grupo de trabalhadores qualificados, eles se queixam com insistência da monotonia e da ausência de desafios ${ }^{2}$ no trabalho. Os técnicos demons- 
Os significados do trabalho segundo técnicos de nível médio

tram valorizar muito as atividades intelectuais, utilizando recorrentemente termos como: "inteligência", "raciocínio", "trabalhar com a cabeça", "trabalhar mais pensando", "capacidade intelectual". Mesmo os que trabalham com equipamentos com tecnologia avançada não identificam aí o anunciado "enriquecimento de tarefas", nem mesmo um maior trabalho "abstrato ou intelectual". Para os trabalhadores técnicos, alimentar softwares especialistas (como os Controladores Lógicos Programáveis - CLPs - ou softwares de testagem de equipamentos etc.) com dados coletados em painéis e planilhas, dar manutenção em equipamentos eletrônicos (o que, em sua maioria, consiste apenas em "trocar plaquinhas"), fazer repetidos testes de qualidade são tarefas monótonas e bastante destituídas de sentido.

Vários entrevistados acreditam que os modernos equipamentos informatizados destituem os seres humanos de seu raciocínio, causando a perda de compreensão dos processos, como o que ocorre, segundo eles, com o uso generalizado das calculadoras científicas e dos computadores. Um número significativo de entrevistados demonstrou frontal resistência a esses equipamentos.

Há entre vários técnicos uma significativa reflexão acerca da tecnologia, que supera a preocupação em dominá-la e alcança âmbitos como a reflexão sobre a dependência tecnológica do país e as políticas de desenvolvimento tecnológico implementadas pelos países centrais que visam apenas ao aumento da produtividade. Eles criticam o modelo tecnológico vigente como calcado no supérfluo, no desperdício pela exagerada obsolescência das tecnologias e no descompromisso social dado pelo crescimento do "desemprego tecnológico". Segundo eles, "só um lado é que ganha".

É um paradoxo! A engenharia, a obrigação dela é trazer inovaçôes. Só que a gente tá buscando inovações e tá esquecendo o lado social, o lado humano. Tá certo, um computador faz um serviço perfeito que 100 homens fazem? Faz. Mas será que esses 100 homens não necessitam comer, não necessitam ter trabalho? Com isso a gente só tá fazendo duas coisas: aumentando as cadeias e os presídios. A tecnologia tá mostrando isso. (Fernando, controle de qualidade em indústria de montagens mecânicas de grande porte)

A implantação de programas de qualidade também não parece seduzi-los. Apesar de admirarem alguns aspectos da racionalização, os 
técnicos vêem os programas de qualidade principalmente como mecanismos de aceleração da produção e redução de postos, ainda que alguns vejam positividade nisso, acreditando que, se a empresa for competitiva e crescer, talvez se abra alguma nova oportunidade para eles. Os programas de qualidade são ainda percebidos como incapazes de transformar a precária qualidade das relações entre as chefias imediatas e os subordinados, um de seus maiores problemas. Na verdade, referências como "trabalho em equipe" e "cooperação" só aparecem de fato como solidariedade de classe, construída e vivida nos interstícios da estrutura empresarial: no almoço, num comentário em voz baixa enquanto se faz uma tarefa conjunta, na entrada e na saída. As experiências em nível de equipes de trabalho são muito limitadas.

Além de tudo, vários programas de qualidade também são vistos como situações falsas. Os procedimentos prescritos são "decorados" por todos para serem repetidos numa possível visita da auditoria. Entretanto, no dia-a-dia, eles não são aplicados e há uma compreensão generalizada, inclusive das chefias, de que eles não se adaptam às condiçôes reais da produção. Isso numa fábrica multinacional de autopeças que enfrenta a competitividade em nível global! ${ }^{3}$

Se há alguma "nova" demanda ao trabalhador em termos de capacitação para as tarefas, ela é muito mais de caráter geral: relacionamento interpessoal para diminuir conflitos, autocontrole, noções básicas de matemática. Os conhecimentos técnicos utilizados são quase sempre específicos dos equipamentos de cada empresa e são repassados ali mesmo, pelos trabalhadores mais experientes, não demandando maior formação técnico-científica.

Oito dos entrevistados demonstram satisfação com as tarefas desempenhadas e metade desses ocupa cargos de gerência. Mesmo assim, a satisfação com as tarefas não os isenta de tensões e contradições, às vezes, dramáticas. Lúcia Bruno, estudando engenheiros "de área" em uma montadora automobilística, discute as atividades desempenhadas por eles, apontando para mudanças de caráter paradoxal que vêm sendo percebidas: de um lado, dos técnicos são "exigidos conhecimentos administrativos, de marketing, técnicas gerenciais e de liderança, de estrutura de custos, legislação trabalhista, relações comerciais, segurança do trabalho, informática" (Bruno, 2000, p. 136). Segundo Luiza, uma das entrevistadas, "o engenheiro hoje tem que ser um $x$-tudo". Ao mesmo 
Os significados do trabalho segundo técnicos de nível médio

tempo, essa ampliação do campo de percepção e atuação vem acompanhada de uma paradoxal redução do espaço e das possibilidades de influenciar decisões relativas a esse amplo campo de atuação. Além disso, crescem as pressões para a aceleração da produção e a redução de custos; elevando-se uma vez mais o estresse também dos engenheiros, que se vêem definitivamente "inseridos na cadeia infernal da produção de valores” (Bruno, 2000, p. 131).

Em situação similar à descrita por Bruno, Hugo e Luiza ressentem-se do excesso de desafios: mostrando-se competentes na gerência de pessoas e processos; eles passaram a ser seguidamente designados para todos os setores problemáticos de suas empresas, o que acaba lhes acarretando um enorme desgaste. Luiza ingressou como técnica numa empresa que comercializa equipamentos importados de distribuição de energia. Galgou rapidamente a chefia do laboratório (manutenção) e passou em seguida a também chefiar as equipes de manutenção em campo, até então francamente problemáticas e deficitárias. Luiza recuperou o setor e ainda outros projetos igualmente deficitários, conseguindo enormes ganhos para a empresa. Entretanto, ao abrir-se uma vaga de gerência, almejada por ela, viu-se preterida em benefício do filho de um deputado com tradicional atuação no setor energético. $\mathrm{O}$ capital técnico perdeu para o capital social. ${ }^{4}$ Apesar de satisfeita com as tarefas realizadas, Luiza acumulou uma grande insatisfação pelo nãoreconhecimento efetivo de seu trabalho.

Os gerentes sentem-se ainda premidos pelas políticas de suas empresas, movidas pela lógica exclusiva do lucro. Uma das contradições que enfrentam é lidar com as constantes demissões de funcionários, diante de qualquer redução na produção.

Então as pessoas perdem o emprego, igual perdeu lá, hoje, vários pais de família... complicado! Cê sente que as pessoas não ligam mais pra isso, só querem ver quanto que elas tão deixando de ganhar. As coisas não podem ser tão imediatistas, né? Acho que tem que tentar segurar: vai dar um treinamento... Isso é muito falado em teoria, mas na prática não funciona assim. Vai dar férias! A empresa, né, o capitalista, ele tem uma visão da empresa que quem tá lá é igual à gente, no dia-a-dia é diferente, porque o cara só vê faturamento e custo. Na verdade aquela pessoa, porque aquela máquina dela hoje não tá produzindo, ela pode estar te atendendo em outras coisas. Pra eles é fácil, os sócios das empresas, né, as pessoas que cobram resultado em cima de faturamento. São eles que tomam as atitudes. Então 
você tá trabalhando numa empresa, você recebe diretrizes. Então essas diretrizes vêm lá de cima e vêm descendo. Então você tem um presidente que tem contato direto com o quê? Dar lucro. Eu não acho que tem que ser diferente. Uma empresa não pode viver dando prejuízo. Mas tem o lado social que tem que ser olhado... Se prega uma coisa na hora que as coisas tão bem. Na hora que tá vendendo bem, cê prega que o funcionário tem que ter produtividade, tem que fazer o possível, que a empresa tem que crescer, mas qualquer caída que ela dá, ele é o primeiro a ir pra rua. $\mathrm{Na}$ hora que a coisa dá uma caidinha, tchau e bênção. (Hugo, gerente de uma das fábricas de siderúrgica multinacional de grande porte)

Oriundo de cargos subalternos, pois ingressou e permaneceu como técnico durante muitos anos, Hugo, mesmo no cargo de gerente, mantém uma postura solidária com os trabalhadores e absorve um enorme estresse pelas contradições de seu cargo, que não lhe possibilitam, individualmente, reverter essa situação.

Outro importante aspecto na construção do significado do trabalho refere-se aos ritmos do cotidiano profissional. $\mathrm{O}$ aprofundamento dos processos de racionalização visando ao aumento de produtividade implantou, ao longo da década de 1990, ritmos extremamente acelerados na já acelerada produção industrial. A grande maioria dos técnicos ressente-se fortemente do ritmo do trabalho, exceção feita para alguns dos que trabalham fora da produção, nos escritórios.

Cada minuto uma máquina ficando parada lá é um sufoco. E é tudo cronometrado e anotado, faz um relatório... isso é importantíssimo! (Robson, manutenção mecânica em siderúrgica multinacional)

A pressão é que é demais! Se a máquina pára, 10, 20 minutos, aparece chefe de tudo quanto é lado: - Vai parar a fábrica, vai parar a fábrica! Vai parar o cliente (a montadora)!!! E essa pressão até prejudica a gente a raciocinar em cima do problema. (Roberto, manutenção mecânica em indústria multinacional de autopeças)

Ainda que imbuídos, desde a infância, em alguns casos, ou pelo menos desde a formação profissional, em todos os casos, de um habitus fortemente ascético, disciplinado e calcado no autocontrole e no desejo de ser competente, os técnicos demonstram rejeitar os ritmos impostos pelas empresas, não só com relação à aceleração da produção, da definição de prazos cada vez mais reduzidos e de metas cada vez mais ambiciosas, como também pela utilização bastante generalizada da pro- 
Os significados do trabalho segundo técnicos de nível médio

dução em sistema de turnos e de letras, em que as empresas funcionam 24 horas por dia, 7 dias na semana. Esse sistema inviabiliza grande parte das atividades da vida pessoal do trabalhador, que se sente prisioneiro da empresa, impossibilitado de estudar, até mesmo de namorar.

\section{O significado das relaçôes sociais no trabalho}

Como cada um dos que hoje ocupam postos de supervisão, chefia e gerência passou pela posição de técnico, muitos deles tendo sido anteriormente trabalhadores semiqualificados ou não-qualificados, temos uma grande riqueza de experiências na trajetória de um mesmo sujeito, que foi se percebendo e sendo percebido, construindo-se e sendo construído em diferentes posições à medida que avançava ou não na carreira. Além disso, essas experiências parecem constituir um tipo específico de "técnico" e de "chefe" ou "gerente": aquele que "veio de baixo", "já sofreu de tudo", "conhece a realidade barra-pesada por dentro".

Porque à medida que você vai crescendo dentro da empresa o pessoal já vai te tratando diferente porque você é chefe. Isso tem muito, viu? Porque você sai lá de baixo, à medida que você vai tendo poder, o pessoal começa... é aquela velha história, né? Antes era Robertinho e depois já começam a te chamar de Dr. Roberto (risos). (Luiza, chefe de equipe de manutenção de equipamentos em campo, de empresa de importação e comércio de equipamentos de distribuição de energia elétrica de alta-tensão)

Mesmo passando a ser reconhecido como engenheiro, a posição do técnico ou do ex-técnico, de seu próprio ponto de vista, é uma particular posição intermediária, complexa e híbrida: identifica-se e diferencia-se dos "operadores" ou do "pessoal do chão de fábrica" ao mesmo tempo em que se identifica e se diferencia dos engenheiros e "chefes". Vejamos como isso acontece.

De acordo com seu sistema classificatório, os técnicos têm interesse em diferenciar-se dos "níveis abaixo", para os quais encontramos as seguintes categorias nativas: "operadores", "pessoal do chão de fábrica", "barra-pesada", "práticos", "peões" (considerado termo discriminatório). Os técnicos buscam diferenciar-se do "nível intelectual", daqueles que "só conversam de mulher e futebol", "falam muito palavrão", "carentes de atenção da chefia", "que não quiseram ou não puderam estudar". Também demonstram interesses corporativos de diferenciação intraclasse, ${ }^{5}$ 
como em situações em que os técnicos diplomados esperam receber salários mais elevados do que quem fez "cursinhos", numa típica atitude de concorrência intraclasse.

Ao mesmo tempo em que se diferenciam, os técnicos identificam-se com os trabalhadores não-qualificados por sua origem familiar e cultural, e por sua trajetória profissional: "eu gosto de jogar truco", "também gosto de papo de novela", "eu gosto de pessoas humildes", "pessoal sem soberba", "conhecem realmente o que fazem", "pessoal que trabalha de verdade". Os entrevistados na sua totalidade demonstraram profunda solidariedade para com os trabalhadores de níveis hierárquicos inferiores, manifestando revolta com o tratamento que vem sendo dispensado a eles dentro das empresas:

O nível de relacionamento é a mesma coisa em todo lugar: os chefes parece que não pensam, só berram. Aí o operador, ele é igual em toda empresa. Ele quer parar a máquina, mesmo, ele quer quebrar a máquina. Além do tratamento mal, o cara ganha pouco. Porque é aquela coisa: o cara ganha mal e ainda é xingado, ainda, pô! Aí passa dos limites. (Roberto)

Os técnicos também se identificam com os operadores, ou até mesmo colocam-se como "peōes" ao se referirem à sua condição subalterna na empresa, como Danilo, ao dizer que não tem acesso à Internet na empresa, pois "Internet é só pros peixe, pros peão, nada!", ou Walmir, ao afirmar a necessidade do operador, idêntica à dele, de ser bem tratado pelo chefe, ser "considerado".

De maneira análoga, os técnicos diferenciam-se ao mesmo tempo em que se identificam com os engenheiros: identificam-se por admirarem e buscarem o reconhecimento profissional e social que aqueles alcançaram (inclusive alguns dos entrevistados), porque "a gente vê ele crescendo profissionalmente", por seu domínio de conhecimentos, "nível intelectual" e pelo nível cultural geral: "é mais maduro". Também se identificam por perceberem que, assim como os técnicos, os engenheiros são igualmente vítimas das leis do mercado que a cada dia impõem maior controle sobre seu tempo e maiores limitações aos seus salários e às suas condições de trabalho.

Ao mesmo tempo, diferenciam-se dos engenheiros. Acreditam que os engenheiros são mais protegidos em seus interesses, como pelo CREA, órgão a que os técnicos são igualmente filiados. Mesmo alguns 
Os significados do trabalho segundo técnicos de nível médio

técnicos entrevistados que são hoje engenheiros marcam sua distinção de outros colegas engenheiros:

Saber respeitar o outro, respeitar mesmo, qualquer pessoa, independente de que nível que esteja, tanto o operário quanto o cara maior. (João Paulo)

Ou no caso de Walmir, estudante de engenharia, que assinala sua diferenciação com relação aos engenheiros originários das camadas médias e superiores e promete a si mesmo não mudar depois que se formar.

Eu acho que as pessoas mais preconceituosas são aquelas que nunca sofreram na vida, e acham que o cara que pega na massa mesmo é uma subpessoa, é um submental, entendeu? Elas são umas maquininhas que formaram, não sofreram nada. Então vai ter a maior dificuldade para se relacionar, não vai saber chegar para o cara lá embaixo e pedir uma coisa na boa. (...) Quando eu for engenheiro eu não vou ficar falando que eu tô feliz demais, tô com o maior tesão porque eu sou chefe da minha empresa. Tomara que eu não mude de idéia, porque não me dá prazer assim essas coisas. (Walmir)

Essa posição intermediária pode ser também chamada de híbri$\mathrm{da},{ }^{6}$ na medida em que compõe sua identidade selecionando elementos de um ou de outro grupo, a partir de valores que se constituem como eixos de seu sistema classificatório: desenvolvimento pessoal, solidariedade, reconhecimento social, humildade, identidade cultural popular, domínio de conhecimentos técnico-científicos. Nessa condição, atuam como mediadores, ${ }^{7}$ às vezes formalmente, como nas situaçôes em que exercem cargos de chefia, mas principalmente de maneira informal, nos interstícios das relações formais, em que atuam como uma espécie de ouvidores e tradutores, especialmente ao lado dos operadores, ajudando-os a se verem sob outra perspectiva que não a dominante e a não se sentirem inferiores ("subpessoa", "submental"), a despeito das normas que prevalecem no cotidiano das empresas.

(...) eu tentava quebrar esse complexo todo, porque eu tinha passado por aquele chão, no nível deles, entendeu? Eu procurava depois suprir as necessidades que eu sabia que eles tinham, pra poder quebrar esse negócio de chefe/peão, chefe/peão. Aí eu me dava bem, o pessoal gostava de mim pra caramba. Eu sempre carreguei essa carga política na boa, sem fingir com ninguém, mas porque eu vivi esse lado. Tô evoluindo, e vou viver o outro lado, mas eu vou sempre estar ali. A minha origem tá ali, não tem jeito. (Walmir) 


\section{As relações de gênero}

Merece destaque a dinâmica particular das relações de gênero em campos profissionais tradicionalmente masculinos, ligados à engenharia, como no caso dos técnicos investigados aqui. Luiza, Solange e Sônia enfrentaram diversos tipos de tratamentos diferenciais e prejudiciais, já amplamente relatados na literatura (menores oportunidades na contratação e nas promoções, salários diferenciados na mesma tarefa). Inicialmente "testadas" pelos companheiros e chefes do sexo masculino, para saber se elas eram "bobas", "frágeis" ou "incompetentes tecnicamente", construíram uma nova identidade feminina. Para isso foi preciso superar as imagens acima, acerca das mulheres, e ainda conquistar reconhecimento num espaço social - os cargos técnicos -, onde até elas próprias estavam acostumadas a só verem homens, sentindo-se, inicialmente, privilegiadas só de estarem ali. Algum tempo depois, refazem sua autoimagem, conquistam diante de si mesmas o status de técnicas competentes e passam a reivindicar seus direitos. Esse processo não é fácil, nem subjetiva, muito menos organizacionalmente. Sônia chegou a perder o emprego por ter movido uma ação judicial por equiparação salarial com os técnicos homens. Nunca mais conseguiu emprego na indústria. Solange, concursada numa empresa então estatal, teve melhores condições para se impor profissionalmente. Chefia hoje um setor. Tanto no caso de Solange quanto no de Luiza, temos mulheres galgando algum nível de chefia e reconstruindo, nesse processo, práticas e representaçóes acerca da questão dos aspectos identitários referentes ao gênero: reconstruindo-se a si mesmas, portanto. Cristina Bruschini e Maria Rosa Lombardi (2000) encontraram uma forte consolidação da presença da mulher em várias ocupações, ao longo dos anos de 1990, com exceção do campo da engenharia. Nessa categoria, a participação feminina atingia $11 \%$ do total de engenheiros em 1990, subindo apenas um ponto porcentual até $1996 .{ }^{8}$ As autoras destacam as áreas de mecânica e metalurgia como verdadeiros guetos masculinos, em que menos de 5\% dos postos são ocupados por mulheres.

Luiza adota, especialmente no mundo do trabalho, a linguagem e o tipo de racionalidade que aí predominam: objetividade, um estilo de tratamento direto das questóes, considerados por ela, pelas colegas e pelos colegas características masculinas, em oposição à "frescura", àquela "coisa muito mole" e à postura "frágil" das mulheres, para as quais 
Os significados do trabalho segundo técnicos de nível médio

ela "não tem paciência". Por isso, acredita-se mais próxima do universo masculino. Seu discurso coloca, o tempo todo, uma sinalização posicional em que a positividade está sempre no pólo masculino ao passo que o pólo feminino é repetidamente identificado de forma negativa. Luiza assume então as representações masculinas, inclusive no que elas têm de discriminatório da mulher, vista como "fresca", "mole", "fofoqueira", "insegura", "simplória". Diante das contradições do mercado na relação com trabalhadores dos diferentes sexos, Luiza assume os discursos do "pólo dominante". Onde buscaria outras referências para sua identidade de gênero que fosse capaz de romper com esses estereótipos?

Fazendo jus às denominadas identidades fragmentárias da modernidade tardia, Luiza, nos finais de semana, anseia por ficar em casa, cuidar das gavetas, ir ao salão arrumar-se, brincar com o cachorro... Realizar os valores da sua família de origem, impossibilitados de manifestar-se no âmbito do trabalho. Ao mesmo tempo, adia o casamento indefinidamente, em benefício da carreira, até que o noivo rompe com ela.

Tanto para as mulheres como para os homens, um outro fator definidor do significado que eles conferem ao trabalho é a possibilidade de carreira dentro da própria empresa. Por isso os empregos mais valorizados são aqueles situados nas grandes empresas. Antes, nas estatais, onde se deposita hoje enorme sentimento de perda. Parecem decorrer no máximo cinco ou seis anos de mercado até que o técnico comece a reestruturar seu projeto inicial de "formar-se técnico, trabalhar na área, mostrar sua competência, fazer sucesso", do qual tanto se orgulhava inicialmente. É esse o período médio para perceberem as efetivas "limitações" (palavra recorrentemente associada a "técnico") a que estão submetidos. Nadya Castro e Antônio Sérgio Guimarães encontraram experiências semelhantes entre petroquímicos baianos, muitos dos quais técnicos de nível médio, como os nossos. Esses trabalhadores percebiam o trabalho como exclusão em virtude de condições como o estrangulamento da carreira, muito semelhante ao experimentado pelos técnicos de nossa pesquisa, e que se aliavam a outros elementos similares aos aqui apontados: as condições de trabalho, o caráter despótico e pouco participativo dos aparatos políticos da produção e a inexistência de regulação da cidadania fabril (Castro e Guimarães, 1992 e 1995). Apesar de não estarem tão submetidos à exclusão material, esses trabalhadores convivem com um número significativo de sinais de exclusão simbólica que contribui para o fortalecimento de seus discursos antipatronais, ao mesmo 
tempo em que os impulsiona para novos projetos, especialmente, no caso de nossos entrevistados, para a universidade, última alternativa vislumbrada para a melhoria de vida. É o mercado que os impele para a universidade, que destrói as ilusōes meritocráticas, são as próprias práticas empresariais que minam as idéias associadas à noção de empregabilidade. Os técnicos dedicam-se, procuram "dar a mais" do que lhes é pedido, aperfeiçoam-se e o que têm em troca? Segundo eles, não há reciprocidade.

\section{As relações com os sindicatos}

Enquanto vivenciam tantas contradiçôes, fazem contato com as práticas sindicais. As reivindicações e situações de negociação nascidas das relaçōes de trabalho (campanhas salariais, decisōes sobre horas extras, a viabilização da continuidade dos estudos, decisões sobre feriados e reposições de horas paradas) fazem emergir claramente a polarização entre a figura da empresa como "patrão", que no cotidiano nem sempre fica muito explicitada, e a figura do trabalhador, que engloba todas as subcategorias que a compõem. Nessa polarização, o sindicato é reconhecido como importante instância na defesa dos direitos dos trabalhadores, pois, no embate direto entre patróes e empregados, "os patrōes são mais fortes", "o trabalhador não pode ir contra senão ele é demitido". O desamparo do trabalhador perante o patrão é facilmente percebido nas situações de "negociação direta" da empresa com os trabalhadores, como, por exemplo, ao "negociar" a reposição de um feriado: a empresa passa, por intermédio das chefias, um abaixo-assinado daqueles que concordam com sua proposta, desfavorável aos trabalhadores. O chefe já passa a lista avisando: "Quem não assinar, cuidado!" Como sobreviver no mundo da empresa sem o sindicato? Apesar dessa posição, consensual entre os entrevistados, apenas 5 entre os 18 entrevistados já participaram de alguma atividade sindical, mesmo assim de maneira pontual ou indireta (uma greve, algumas assembléias, apenas respeitar a greve), ainda que todos acompanhem as negociações das campanhas salariais, mostrando-se muito bem informados.

Tentemos compreender essas posturas. Em primeiro lugar, há uma espécie de "tradição" que eles já encontraram instalada na indústria, de que pessoal especializado não participa de greve, só os operadores de máquina param. Mas se esse fator contribui para sua postura, 
Os significados do trabalho segundo técnicos de nível médio

não é o único. Mesmo muitos sendo sindicalizados, a imagem, praticamente consensual entre todos, é a de que as direções dos sindicatos são "radicais" e "distantes". Os técnicos demonstram impaciência com reivindicações sindicais impossíveis, como índices de reposição "totalmente fora da realidade" ou "pautas que reivindicam tudo". Segundo eles, os sindicatos não estão realmente dispostos a negociar e partem para a greve prematuramente, sem esgotar todas as possibilidades de negociação. Acreditam que isso acontece porque há interesses políticos, além da defesa do trabalhador. Olacir, por exemplo, vê os sindicatos como movimentos com uma postura "arcaica", que não acompanharam a sociedade, porque, mesmo sabendo que os trabalhadores hoje já não se dispõem a fazer greve, o sindicato insiste nessa modalidade única de luta. Os patrôes então podem, ainda segundo Olacir, ficar tranqüilos, porque sabem que não haverá greve e, portanto, nenhum outro tipo de pressão. Ele critica o seu sindicato (de metalúrgicos) por só fazer contato com a categoria em véspera de dissídio, por meio dos "irritantes" carros de som nas portas das fábricas. Durante o restante do ano, nenhuma atividade é feita, poucas informações são oferecidas aos trabalhadores pelos sindicatos acerca dos inúmeros temas de seu interesse. Por isso o sindicato é conhecido, entre os colegas de trabalho de Olacir, como "sindigato, porque só sabem pegar o dinheiro dos funcionários".

O sindicato também não parece ser instância de informação. Roberto esteve num ciclo de debates promovido pela prefeitura. Lá, ouviu técnicos do DIEESE questionando a noção de empregabilidade, idéias com as quais nunca havia entrado em contato antes. Nunca teve notícias de nada parecido promovido por seu sindicato (de metalúrgicos). Se o movimento sindical vive uma crise de legitimidade, não parece ser, segundo esses depoimentos, por não ter reconhecida sua importância pelos trabalhadores. Entretanto, os técnicos parecem não se sentir ouvidos pelos sindicatos em nenhum momento: suas avaliações, suas propostas, suas necessidades e reivindicações, como preferência de horário central para os trabalhadores-estudantes, rodízio de tarefas, instâncias de avaliação da qualidade das relações entre chefias e trabalhadores, novas formas de pressão e luta.

As experiências de trabalhadores inseridos em posições relativamente "privilegiadas" no setor formal vêm levando esses sujeitos a relativizarem a posição central já ocupada pelo trabalho em seus interesses. Não que o trabalho deixe de ser instância privilegiada de seus 
projetos: ele é a condição primeira para a realização de todas as demais, além de elemento-chave em toda a constituição de suas identidades. Entretanto, a ausência de reciprocidade no mercado faz com que o trabalho passe, cada vez mais, a ser visto como instrumento, como meio. No que, sem dúvida, esses sujeitos podem estar, de alguma forma, avançando, na história das classes trabalhadoras brasileiras, na medida em que deixam de depositar todas as energias e projetos de realização exclusivamente no âmbito do trabalho, desenvolvendo uma profunda visão crítica a esse respeito e passando a buscar outros espaços de realização: os estudos, a arte, o lazer, um tanto negligenciados pelas gerações que chegaram a acreditar numa realização plena por meio unicamente da esfera do trabalho.

\section{Conclusões}

De maneira geral, fica patente que, se o mercado explora e exclui, ele também abre perspectivas, desnuda relações, oportuniza experiências e é incapaz de conter o fazer-se (Thompson, 1997) desses trabalhadores. Fundados numa visão de mundo própria, construída no interior da cultura das classes trabalhadoras, esses técnicos se colocam diante dos códigos dominantes no mercado como sujeitos dotados de reflexividade (Giddens, 1997) e de um referencial simbólico que possibilita que eles, percebendo-se sujeitados no cotidiano do trabalho (à hierarquia, às rotinas de trabalho, aos ritmos da produção, aos baixos salários, às discriminações de gênero, às políticas sindicais), elaborem essas experiências de forma própria, sendo capazes de se verem de forma independente dessas estruturas e práticas, ainda que com limitações.

É importante notar que nem todos os meandros e as sutilezas do mundo do trabalho (o sistema meritocrático, as relações entre tecnologia e política, entre salário e políticas industriais transnacionais, entre empregabilidade do trabalhador e lucratividade das empresas, entre qualificação, sobreescolarização do trabalhador e desqualificação do trabalho, entre o "sindicalismo dos decibéis" e as experiências cotidianas dos trabalhadores etc.) aparecem nas representações de todos os entrevistados. Muito poucos desses temas foram sequer mencionados, mesmo assim de forma isolada e ocasional, no período em que receberam a qualificação como técnicos, muito menos pelos sindicatos e partidos de esquerda. Em função de suas trajetórias, lhes é dado perceber aspectos 
Os significados do trabalho segundo técnicos de nível médio

parciais da realidade. Sabemos que isso é verdade para todo e qualquer sujeito, individual ou social: nossa visão é sempre parcial, limitada e, ao mesmo tempo, única, por percebermos aspectos do real só dados a ver a partir do campo de possibilidades concreto em que nos situamos. Aí estão a nossa riqueza e a nossa limitação. Entretanto, descortinar esse conjunto de experiências sem dúvida nos permite esboçar ao mesmo tempo um mapa e um observatório (Passeron, 1991) do que seja a experiência dos técnicos de nível médio no mundo do trabalho. Um mapa, porque permite identificar elementos, relações, estruturas, tensões, limites e concepções que compõem tal experiência. Um observatório, porque, ao mapear esses elementos, construímos postos de observação para abordálos, hoje e em situações futuras.

Com o presente mapa apontam-se, por meio do olhar desses técnicos, pistas para pensarmos em currículos de formação técnica, sindical e humana que dialoguem efetivamente com as reais experiências daqueles que ocupam esse tipo de posição no mercado e na sociedade.

Recebido em setembro de 2004 e aprovado em maio de 2005.

\section{Notas}

1. Salário mínimo necessário: salário mínimo de acordo com o preceito constitucional "salário mínimo fixado em lei, nacionalmente unificado, capaz de atender às suas necessidades vitais básicas e às de sua família, como moradia, alimentação, educação, saúde, lazer, vestuário, higiene, transporte e previdência social, reajustado periodicamente, de modo a preservar o poder aquisitivo, vedada sua vinculação para qualquer fim" (Constituição da República Federativa do Brasil, capítulo II, Dos Direitos Sociais, artigo 7o, inciso IV). "Ponderando-se o gasto familiar, chegamos ao salário mínimo necessário" (DIEESE, 2003). Em dezembro de 2002 esse valor estava estimado em $\mathrm{R} \$ 1.378,19$

2. Os "desafios" são uma das categorias básicas do universo cultural desses sujeitos, com raízes na cultura do trabalho de suas famílias de origem e/ou nas experiências vividas e no habitus adquirido durante sua formação profissional numa instituição fortemente exigente em termos acadêmicos.

3. Constataçōes semelhantes foram feitas por Bruno (2000) na montadora multinacional situada em São Bernardo do Campo (SP).

4. Estou me referindo aqui ao conceito clássico de Bourdieu de capital, referido ao conceito de campo, visto como um espaço onde se manifestam relaçōes de poder estruturadas a partir da distribuição desigual de um quantum do(s) tipo(s) de capital valorizado(s) naquele campo (científico, social, acadêmico, cultural etc.), que é detido por cada um dos agentes ali localizados e os quais, em função disso, localizar-se-ão, no interior do campo, em algum ponto entre seus dois pólos opostos: o dos dominantes, onde se localizam os que pos- 
suem maior quantum de capital, e o dos dominados, em cujo extremo se localizam os destituídos daquele capital (Bourdieu, 1983, p. 21).

5. Segundo Nadya Castro (1992 e 1993), a natureza social da qualificação profissional se constrói por meio de processos artificiais de delimitação e de classificação de campos que conferem status social, e um desses processos artificiais seria justamente a construção de signos de diferenciação entre os próprios trabalhadores (intraclasse).

6. Segundo Nestor Canclini, as identidades híbridas, diferente daquelas que exigem lealdades absolutas dos membros de cada grupo, apontam para "maneiras desiguais de os grupos se apropriarem dos elementos de várias sociedades” (1997, p. 142). As identidades nas sociedades complexas são poliglotas, multiétnicas, migrantes, feitas com elementos mesclados de várias culturas.

7. Karina Kuschnir (2001) define o mediador como aquele sujeito que, possuindo múltiplas identidades construídas pela circulação, ao longo de sua trajetória de vida, entre diferentes universos com valores e visões de mundo mais ou menos distintas, atua como ponte, elemento de comunicação entre os universos pelos quais transita.

8. No mesmo período, entre 1990 e 1996, a participação da mulher cresce de 31,4 para 35,9 na área do direito (advogados, procuradores, juízes, promotores e consultores jurídicos) e cresce ainda de 47,3 para 53,5 na área da arquitetura (Bruschini \& Lombardi, 2000).

\section{Referências bibliográficas}

BOURDIEU, P. Sociologia. São Paulo: Ática, 1983.

BRUNO, L. Trabalho e atribuições dos engenheiros em uma montadora reestruturada. In: BRUNO, L.; LAUDARES, J.B. Trabalho e formação do engenheiro. Belo Horizonte: FUMARC/PUC-MG, 2000. p. 123-154.

BRUSCHINI, C.; LOMBARDI, M.R. A bipolaridade do trabalho feminino no Brasil contemporâneo. Cadernos de Pesquisa, São Paulo, n. 110, p. 67-104, jul. 2000.

CANCLINI, N. G. Consumidores e cidadãos. Rio de Janeiro: UfRJ, 1997.

CASTRO, N.A. Organização do trabalho, qualificação e controle na indústria moderna. In: Trabalho \& Educação: coletânea CBE. Campinas: Papirus; CEDEs; São Paulo: ANDE; ANPED, 1992. p. 69-86.

CASTRO, N.A. Qualificação, qualidades e classificações. Educação \& Sociedade, Campinas, v. 14, p. 211-224, ago. 1993.

CASTRO, N.; GUIMARĀES, A.S.A. Trabalhadores afluentes, indústrias recentes: revisitando a tese da aristocracia operária. Dados - Revista de Ciências Sociais, Rio de Janeiro, v. 35, n. 2, p. 173-191, 1992. 
Os significados do trabalho segundo técnicos de nível médio

DEPARTAMENTO INTERSINDICAL DE ESTUDOS ESTATISTICOS E ECONOMICOS (DIEESE). Informativo Eletrônico, v. 4, n. 35, fev. 2003.

GIDDENS, A. Modernidade e identidade pessoal. Oeiras: Celta, 1997.

KUSCHNIR, K. Trajetória, projeto e mediação política. In: KUSCHNIR, K.; Velho, G. Mediação, cultura e política. Rio de Janeiro: Aeroplano, 2001.

PASSERON, J.-C. O mapa e o observatório: alguns problemas atuais da pesquisa em sociologia da educação. Teoria \& Educação, Porto Alegre, v. 1, n. 3, p. 69-88, 1991.

THOMPSON, E.P. A formação da classe operária inglesa. Rio de Janeiro: Paz \& Terra, 1997. v.1.

TOURAINE, A. Crítica da modernidade. Petrópolis: Vozes, 1994. 